Georgia State University

ScholarWorks @ Georgia State University

\title{
Black Homebuying after the Crisis: Appreciation Patterns in Fifteen Large Metropolitan Areas
}

Daniel Immergluck

Georgia State University, dimmergluck@gsu.edu

Stephanie Earl

USI - AYSPS

Allison Powell

USI - AYSPS

Follow this and additional works at: https://scholarworks.gsu.edu/urban_studies_institute

Part of the Urban Studies and Planning Commons

\section{Recommended Citation}

Immergluck, Daniel; Earl, Stephanie; and Powell, Allison, "Black Homebuying after the Crisis: Appreciation Patterns in Fifteen Large Metropolitan Areas" (2019). USI Publications. 35.

https://scholarworks.gsu.edu/urban_studies_institute/35

This Article is brought to you for free and open access by the Urban Studies Institute at ScholarWorks @ Georgia State University. It has been accepted for inclusion in USI Publications by an authorized administrator of ScholarWorks @ Georgia State University. For more information, please contact scholarworks@gsu.edu. 
 \\ Black Homebuying after the Crisis: Appreciation Patterns in Fifteen Large Metropolitan Areas
}

Dan Immergluck*, Stephanie Earl, and Allison Powell

Urban Studies Institute, Georgia State University

\begin{abstract}
Some have questioned the financial wisdom of homeownership and, especially, Black homeownership. This is understandable because the mortgage crisis dealt heavy blows to Black homeowners. One concern is that home values may not appreciate as much where Blacks purchase homes. We examine how Black homebuyers fared compared to White and Latino buyers in terms of home appreciation during the 2012 to 2017 recovery. We examine appreciation rates by race and ethnicity across 15 metros. We then estimate the relationship between appreciation and the race and ethnicity of the homebuyer, as well as characteristics of the neighborhood where the home is purchased. We find Blacks saw higher appreciation rates than Whites in high- and medium-appreciation metros, but not in low-appreciation metros. We also find that in medium- and high-appreciation metros, buyers in racially diverse neighborhoods tended to see higher levels of appreciation. Also in higherappreciation metros, those buying in lower-income neighborhoods tended to see higher appreciation rates, while those in low-appreciation metros did not.
\end{abstract}

\section{INTRODUCTION}

In the wake of the U.S. mortgage crisis, some have questioned the financial wisdom of homeownership generally and, especially, Black homeownership (Dickerson 2012; Emmons 2017; Shlay 2015). This skepticism of Black homeownership is understandable, in part because the mortgage crisis dealt particularly heavy blows to Black homeowners and neighborhoods (Immergluck 2015; Reid et al. 2017). However, as the broader housing market recovered, Blacks did not benefit as much as they might have due to their relatively low rates of homebuying following the crisis as well as the relatively lower values of the homes that they were able to buy (Goodman et al. 2014). While the reasons for depressed homebuying rates among Blacks are beyond the scope of this study, they may involve a combination of factors, including damaged credit histories and loss of wealth from the foreclosure crisis, weak enforcement of fair lending and community reinvestment policies, weaker earnings and employment in the wake of the Great Recession, and other factors.

One persistent concern around the issue of Black homeownership is the notion that home values may not appreciate as much in the places where Blacks are likely to purchase homes. Using census-tract-level home price appreciation data, we estimate the 2012 to

*Correspondence should be addressed to Dan Immergluck, Professor, Urban Studies Institute, Georgia State University, 55 Park Place, Atlanta, GA 30303; dimmergluck@gsu.edu. 
2017 appreciation rates of homes purchased by 2012 buyers using mortgages, and break these out by the race and ethnicity of homebuyers in 15 large metropolitan areas. We then look at how appreciation patterns vary across the 15 metros. Given the reversal of falling home values into rising ones in most parts of the country around 2012, we suggest that the use of a small-area home price index should provide more accurate estimates of home values than the use of measures based on surveys, such as the American Community Survey. Finally, we conduct multivariate analysis to understand the neighborhoodand household-level factors associated with higher or lower levels of appreciation. We conclude with a set of policy recommendations.

\section{EVIDENCE ON THE FINANCIAL PROS AND CONS OF BLACK HOMEOWNERSHIP}

The question of Black homeownership is a complex one, dependent on time and place. In highly volatile markets, when risks of sudden declines in values and large foreclosure spikes, homebuying, especially if not carefully financed, can expose households to high risks of negative consequences. Conversely, during periods of more stable appreciation, Black homebuying may offer households with limited financial assets the opportunity to grow those assets, thereby potentially reducing racial wealth inequality over time.

Herbert et al. (2013) point to a number of ways that homeownership can help households gain wealth. These include: (1) providing a "forced savings" mechanism where a growing portion of housing payments go towards gaining equity in the home, (2) appreciation of the home, (3) the leveraging of the asset appreciation through requiring a modest downpayment while receiving the bulk of the gains from appreciation, (4) serving as a hedge against unpredictable increases in rents (and land values), and (5) potential tax advantages (although recent tax changes are likely to concentrate these benefits even more among higher-income homeowners).

Herbert et al. (2013) find that, between 1975 and 2012, the annual appreciation of house prices averaged 0.8 percentage points above inflation (that is, the real appreciation rate). (Note that this period includes the subprime bust of the late 2000s.) This may not sound like a great deal, but compounded over 30 years even this modest appreciation rate will result in a real, inflation-adjusted gain of 26 percent in home value. This is not the end of the story. The use of a modest downpayment allows for the amplification of the return on the homebuyers' own investment through leverage. Herbert et al. (2013) give the example of a homebuyer putting down 5 percent for a home that appreciates at a moderate 4 percent annual rate. After five years, the home will have appreciated nearly 22 percent. After allowing for selling costs of 6 percent, this would represent an annualized rate of return of 31 percent on the initial downpayment. (We present a more complete analysis of the return on investment of homebuying later in the paper using appreciation data.)

In addition to the benefit of leveraging appreciation, the use of smaller downpayments reduces the amount of liquid assets that the family has to invest in the home up front. Smaller downpayments allow households to invest some savings in other assets, retain some savings for the event of adverse events, and gain greater leverage of the home's appreciation. If a family does lose its home to foreclosures, it will lose a smaller investment than if it had made a larger downpayment. ${ }^{1}$ 
A substantial number of studies have examined the financial returns to homeownership to different ethnoracial groups, although most have covered periods prior to the mortgage crisis. For example, Reid (2005) used data from the Panel Study of Income Dynamics (PSID) from 1976 through 1994 and found that, while minority buyers typically built much less wealth than higher-income and White households, the amount of their housing wealth was significant and many times larger than other forms of wealth. She also found that Black renters held essentially no wealth at the end of the study period. Boehm and Schlottmann (2004) also used PSID data to study homebuying from 1984 through 1992. They found that minorities did gain wealth from homeownership but that the gains, not surprisingly, were much smaller than the gains among higher-income Whites, who tend to purchase more expensive homes. Shapiro et al. (2013) employed the PSID from 1984 through 2009 and found that longer homeownership durations among Whites accounted for 27 percent of the additional appreciation that they experienced as compared to Blacks. Bostic and Lee (2009) simulated the wealth accumulation arising from lower-income homebuying. They also found that the holding period was a critical factor in determining the asset-building benefits of homeownership.

The research above examined Black homeownership outcomes prior to the end of the U.S. mortgage crisis. While the crisis was of a magnitude not experienced since at least the 1930s, it is important to recognize the disproportionate effects it had on Black homeownership rates and the loss of Black wealth. Before the 2010 Dodd-Frank Act, regulation of high-risk and high-cost mortgage lending was very limited (Immergluck 2009). Subprime home purchase lending was allowed to grow rapidly in the early 2000s. Such loans included high rates and fees and risk-inducing loan terms, and were underwritten at high payment-to-income ratios, all of which contributed to higher default and foreclosure rates. Blacks were targeted with predatory and subprime mortgages during this period (Bayer et al. 2017; Bhutta and Ringo 2014; Reid et al. 2017; Steil et al. 2018). Bayer et al. (2017) examined racial differences in subprime lending in seven metropolitan areas from 2004 to 2007 and, after controlling for credit score and other risk factors, Blacks were 103 percent more likely to receive subprime home purchase loans than White borrowers. Reid et al. (2017) found that, after controlling for a wide variety of loan-level characteristics, Blacks paid significantly higher interest rates than Whites and were significantly more likely to receive a loan with a prepayment penalty, a balloon payment, or other characteristics often associated with predatory lending.

Blacks were also more likely than Whites to end up in foreclosure during the crisis, losing the equity in their homes and experiencing a variety of other harms. Reid et al. (2017) found that the predatory loan features common among subprime loans made to Blacks were strongly associated with higher levels of mortgage default. Overall, for loans originated from 2004 to 2007, 28 percent of Black homebuyers had lost their homes to foreclosure or were seriously delinquent by early 2013, more than twice the rate for White households.

Newman and Holupka (2016) used PSID survey data through to 2011 and found that, during the 2000s, Black first-time homebuyers generally lost wealth. New Black homebuyers during the peak of the subprime boom fared poorly compared to Whites. In 2007, the median White buyer lost about $\$ 8,000$ more than comparable renters, while the median Black buyer lost more than twice that amount, at $\$ 19,000$. Faber and Ellen (2016) also found that Black long-term owners also lost more equity than Whites during the 2003 to 2009 period. 
Taking a longer view on the impact of the 2000s, Herbert et al. (2013) analyzed the Survey of Consumer Finances (SCF) to find that despite the losses caused by the subprime crisis, average, inflation-adjusted home equity in 2010 was still higher on average than in 1995. While Whites and higher-income households experienced the largest gains, Black households also experience a substantial inflation-adjusted gain of 39 percent. However, more recent research by Emmons (2017), also using the SCF, suggested that Black home equity continued to fall from 2010 to 2013, so that, while still above the 1995 level, real appreciation over the 1995 to 2013 period was more modest.

The subprime crisis dealt a heavy blow to Black homeownership. After rising during the 1990s, before the 2000s subprime boom, the national Black homeownership rate reversed course and began falling in late 2004 from a high of just over 49 percent to about 42 percent by 2016, where it has generally stayed since then (Drew 2018). This means that the Black homeownership rate fell about 7 percentage points on a base of 49 percent, which amounts to about just under a 15 percent decline in the rate from its peak. Meanwhile, the Latino homeownership rate began falling in 2007 as sand state foreclosures spiked, but then began rebounding significantly beginning in 2015 . The 2018 Latino homeownership rate is about 3.6 percentage points below its peak of 50 percent, or about 7 percent below that peak.

Beyond their effects on households, foreclosures hit Black neighborhoods hard, leaving vacant and abandoned properties, lower property values, and underwater homeowners (Immergluck 2015). In many Black neighborhoods, property values recovered more slowly from the crisis than in White areas, and homeowners remained underwater for longer periods of time (Raymond 2018; Raymond et al. 2016).

Notwithstanding the evidence that Black neighborhoods recovered more slowly from the mortgage crisis, recent evidence suggests that gains in Black home equity began sometime around 2013, depending on the metropolitan area. The 2016 Survey of Consumer Finances (SCF) revealed that from 2013 to 2016, Black homeowners saw slightly greater appreciation than Whites (13.1 vs. 11.6 percent), while Latinos saw an increase of almost 20 percent (Federal Reserve Board 2017). One note of caution on studies using data sets such as the SCF or PSID is that they rely on owner assessments of home values and not sales-based data, such as a home price index. In a recovering market, it might be expected that owner estimates lag true market values (Bucholz et al. 2016).

Goodman and Mayer (2018) suggest that the evidence used to argue against minority homeownership is inconclusive and that with appropriate mortgage regulation in place, more households should be able to benefit from homeownership. Along these lines, Grinstein-Weiss et al. (2013) found that even during the calamitous period of 2005 to 2008, low- and medium-income homeowners receiving prime loans accumulated more assets than did otherwise similar renters.

\section{LOW LEVELS OF BLACK HOMEBUYING AFTER THE MORTGAGE CRISIS}

Tight mortgage markets, damaged credit histories, a flight by lenders to perceived "safety," reduced attention to fair lending and community reinvestment policies, and a weak job market in the early 2010s may have all contributed in various ways to reduce Black homebuying following the crisis. Researchers at the Urban Institute compared 
home purchase lending in 2012 to lending in 2001, a year they consider a relatively healthy year for home purchases that predated the subprime boom (Goodman et al. 2014). They found that 2012 home purchase lending to Whites was down 41 percent compared to 2001 levels, while lending to Blacks was down 55 percent.

If Blacks are pushed out of the homeownership market via foreclosures, and disproportionately kept out of it by tight mortgage markets or a lack of attention to fair lending and community reinvestment policy, then they may be put in a long-term position of suffering disproportionate losses during times of foreclosure and value decline, while also not having sufficient opportunities to share in the broader market recovery. In such a system, over time, Blacks may repeatedly bear a disproportionate share of the downside of housing markets, without sharing in the upsides. This, in turn, could lead to greater wealth inequality in the long term. Beyond this, being relegated to a volatile rental market can mean having fewer choices of where to live (as rental housing is sometimes effectively excluded from many neighborhoods), being subject to rapid rent increases and eviction, and attaining limited housing and location stability, which can be especially important to families with children.

Using Home Mortgage Disclosure Act (HMDA) data and focusing on Black homebuyers, we examine the homebuying patterns of households purchasing homes with a mortgage in 2012, generally at the beginning of the national recovery in home values after the crisis. Using a tract-level home price index produced by the Federal Housing Finance Agency (FHFA), we are able to estimate home appreciation patterns over the 2012 to 2017 period for Black households who purchased homes in 2012 and compare those to the patterns of White, Latino, and Asian homebuyers. We do this for 15 large metropolitan areas where the FHFA data provide tract-level home price changes for a very large share (over 85 percent) of Black home purchase loans made in 2012.

\section{DATA AND METHODS}

Our principal source of data on homebuying patterns is federal HMDA data, which are submitted to federal mortgage and banking regulators annually by mortgage lenders. HMDA data include detailed information on applications for home mortgage loans, including whether the loan was originated, the race and income of the applicant, the size of the loan, the census tract in which the home is located, and other variables. HMDA covers the vast majority of home purchase lending in the U.S., excluding only some very small lenders. While a significant share of single-family home purchases is "all-cash," i.e., made without a mortgage, the bulk of such purchasers are investors and not owner-occupiers, and so are not of interest here. In addition to HMDA data, we also use data from the 2016 five-year American Community Survey (ACS) at the census tract level, and a relatively new home price index provided by the Federal Housing Finance Agency that is available at the tract level, called here the "HPI" for housing price index (Bogin et al. 2016a).

Our interest is in large metropolitan areas, and so we began by examining HMDA and HPI data for the 50 largest metropolitan areas. Unfortunately, the HPI data are not available for all census tracts. This is because in some tracts there are too few transactions with which to construct the index. The index is based on repeated sales of the same properties, so if an insufficient number of properties are sold repeatedly in a tract, an 
TABLE 1. Housing and Demographic Characteristics for 15 Large Metropolitan Areas

\begin{tabular}{|c|c|c|c|c|c|c|}
\hline $\begin{array}{l}\text { Metropolitan } \\
\text { Area }\end{array}$ & $\begin{array}{c}\text { Home Price } \\
\text { Appreciation, } \\
2012 \text { to } 2017^{1}\end{array}$ & $\begin{array}{l}\text { Percent } \\
\text { Black }^{2}\end{array}$ & $\begin{array}{l}\text { Percent } \\
\text { Latino }^{2}\end{array}$ & $\begin{array}{l}\text { Percent } \\
\text { Asian }^{2}\end{array}$ & $\begin{array}{l}\text { Median } \\
\text { Home } \\
\text { Value }^{2}\end{array}$ & $\begin{array}{c}\text { Median } \\
\text { Household } \\
\text { Income }^{2}\end{array}$ \\
\hline Atlanta & $42.4 \%$ & $34.1 \%$ & $9.8 \%$ & $5.7 \%$ & $\$ 197,700$ & $\$ 62,613$ \\
\hline Birmingham & $14.4 \%$ & $28.3 \%$ & $4.2 \%$ & $1.3 \%$ & $\$ 154,000$ & $\$ 52,226$ \\
\hline Boston & $26.9 \%$ & $8.1 \%$ & $10.0 \%$ & $7.8 \%$ & $\$ 412,700$ & $\$ 82,380$ \\
\hline Cincinnati & $15.5 \%$ & $12.3 \%$ & $3.0 \%$ & $2.5 \%$ & $\$ 165,200$ & $\$ 60,260$ \\
\hline Columbus & $26.9 \%$ & $15.3 \%$ & $3.8 \%$ & $3.9 \%$ & $\$ 172,200$ & $\$ 60,294$ \\
\hline Indianapolis & $18.3 \%$ & $15.1 \%$ & $6.3 \%$ & $3.0 \%$ & $\$ 153,500$ & $\$ 56,750$ \\
\hline Los Angeles & $51.1 \%$ & $6.6 \%$ & $44.8 \%$ & $15.7 \%$ & $\$ 578,200$ & $\$ 65,950$ \\
\hline Louisville & $18.6 \%$ & $14.3 \%$ & $4.3 \%$ & $2.0 \%$ & $\$ 162,100$ & $\$ 54,546$ \\
\hline Minneapolis & $30.6 \%$ & $8.1 \%$ & $5.6 \%$ & $6.4 \%$ & $\$ 240,500$ & $\$ 73,231$ \\
\hline Nashville & $41.1 \%$ & $15.3 \%$ & $7.0 \%$ & $2.7 \%$ & $\$ 208,900$ & $\$ 60,030$ \\
\hline Raleigh & $27.0 \%$ & $20.1 \%$ & $9.9 \%$ & $5.4 \%$ & $\$ 237,700$ & $\$ 71,685$ \\
\hline Richmond & $19.2 \%$ & $29.3 \%$ & $5.6 \%$ & $3.8 \%$ & $\$ 227,200$ & $\$ 62,929$ \\
\hline Riverside & $65.4 \%$ & $7.4 \%$ & $50.1 \%$ & $6.5 \%$ & $\$ 318,900$ & $\$ 58,236$ \\
\hline Sacramento & $66.2 \%$ & $7.0 \%$ & $21.2 \%$ & $12.7 \%$ & $\$ 363,300$ & $\$ 64,052$ \\
\hline St. Louis & $13.8 \%$ & $18.1 \%$ & $3.0 \%$ & $2.5 \%$ & $\$ 169,200$ & $\$ 59,780$ \\
\hline
\end{tabular}

${ }^{1}$ From Federal Housing Finance Agency metropolitan-level home price index, nominal (not adjusted for inflation).

${ }^{2}$ From 2016 American Community Survey, 1-year sample.

index value is not provided for that tract. Of the more than 37,000 tracts in the 50 largest metropolitan areas, over 11,000 (about 30 percent) are missing tract-level HPIs.

Because this level of missing HPI data would severely limit what we could learn from our analyses, we reduced the number of the metropolitan areas, focusing on keeping those where HPI data was available for the bulk of home purchase loans. ${ }^{2}$ We first identified five outlier metropolitan areas where the share of all home purchase loans that were located in HPI-missing tracts was above 35 percent. These included Houston, Las Vegas, San Antonio, Miami, and Phoenix. However, we remained concerned that the share of loans in HPI-missing tracts, especially loans to Blacks, was too large in many of the remaining 45 metropolitan areas. We then identified 18 metropolitan areas in which the share of Black loans in HPI-missing tracts was below 15 percent. Because we found that these metros, as a group, had a smaller share of Black purchases than the larger set of metros, we eliminated three additional metros with low Black loan shares (Salt Lake City, Portland, and San Francisco). The remaining set of 15 metropolitan areas had a Black share of home purchase loans of 7.84 percent, very close to the 7.96 percent for the larger sample. We use these 15 metropolitan areas as our set of metros for examining Black homebuying more closely.

Table 1 shows that these fifteen metros are diverse geographically, demographically, and in terms of housing market appreciation. They range from economically weaker regions with lower levels of home price appreciation such as St. Louis and Birmingham to markets with very high levels of appreciation such as Riverside and Sacramento. The metros in the West tend to have larger Latino and Asian populations and smaller Black populations than the other metropolitan areas, with the metros in the South tending to have the largest Black populations. While we do not assert that these 15 metros are closely representative of large U.S. metros, they do provide a good deal of variation in demographics, housing cost levels, and housing market trajectories. 
Metro Price vs. Price in 2000

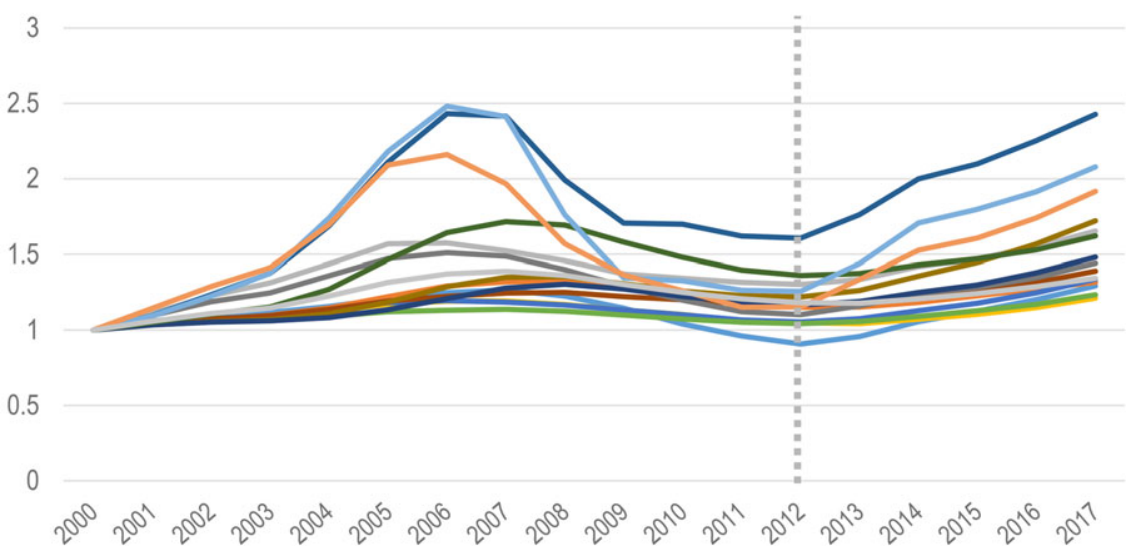

FIG. 1. Home value trajectories for 15 metros, 2000 to 2017.

[Color figure can be viewed at wileyonlinelibrary.com]

Source: Federal Housing Finance Agency Metropolitan Home Price Index

\section{POST-CRISIS BLACK HOMEBUYING AND NEIGHBORHOOD VALUE TRAJECTORIES, 2012 TO 2017}

We begin by examining mortgage-financed homebuying in the fifteen metropolitan areas. There were just over 386,000 home purchase loans made in the fifteen metropolitan areas in 2012. Of these, just under 349,000, or approximately 90 percent, were made on houses in tracts where a change in HPI could be calculated for the 2012 to 2017 period. Moreover, 91 percent of the loans to Blacks were made in tracts where a change in HPI could be calculated. By combining the HPI data with the HMDA data, we estimated the 2012 and 2017 values of each of these 349,000 homes.

We chose 2012 as the initial year of the 5-year recovery period based on examining the trajectories of home values in the 15 metropolitan areas. Figure 1 plots the Federal Housing Finance Agency metropolitan home price index, using 2000 as a base year, from 2000 to 2017. It shows that the bottom of home values generally occurred in 2012. For twelve out of the 15 metros, 2012 was the year in which the metro HPI hit its minimum value after the mortgage crisis, and in the other three metros, the index for that year was less than one point from the minimum (which was in an adjacent year, either 2011 or 2013).

The HMDA data provide an initial loan amount and, depending on the type of loan, the purchase price of the house (and thus the initial 2012 value) was estimated. Average downpayments for different types of loans were obtained from recent studies and applied (Urban Institute 2016, 2017)..$^{3}$ To estimate the 2017 value of each home purchased in 2012, the HPI change factor for the census tract in which the house was located was applied. So, for example, if the estimated purchase price of a house in 2012 was $\$ 100,000$, and the 2012-to-2017 HPI change factor was 1.40, the estimated 2017 value was calculated as $\$ 140,000$. ${ }^{4}$ The HPI change factor is a nominal measure, so the gain in estimated value is not adjusted for inflation. 
TABLE 2. Estimated Appreciation Rates for 2012 Homebuyers Over the 2012 to 2017 Period, 15 Large Metropolitan Areas

\begin{tabular}{|c|c|c|c|c|c|c|c|}
\hline \multirow[b]{2}{*}{ Race/Ethnicity } & \multirow[b]{2}{*}{$\begin{array}{c}\text { Mean } \\
\text { Appreciation }\end{array}$} & \multirow[b]{2}{*}{$\begin{array}{c}\text { Median } \\
\text { Appreciation }\end{array}$} & \multicolumn{5}{|c|}{ Percent of 2012 Homebuyers by Appreciation Range } \\
\hline & & & $\begin{array}{c}5 \% \text { or } \\
\text { Less }\end{array}$ & $\begin{array}{l}5.1 \text { to } \\
19.9 \%\end{array}$ & $\begin{array}{l}20 \text { to } \\
39.9 \%\end{array}$ & $\begin{array}{l}40 \text { to } \\
59.9 \%\end{array}$ & $60 \%+$ \\
\hline Black & $40.0 \%$ & $38.2 \%$ & $3.2 \%$ & $22.4 \%$ & $26.6 \%$ & $28.5 \%$ & $19.3 \%$ \\
\hline Asian & $46.9 \%$ & $45.7 \%$ & $0.5 \%$ & $7.3 \%$ & $29.8 \%$ & $41.2 \%$ & $21.2 \%$ \\
\hline Latino & $64.7 \%$ & $63.7 \%$ & $0.3 \%$ & $3.6 \%$ & $9.9 \%$ & $29.1 \%$ & $57.1 \%$ \\
\hline White & $34.4 \%$ & $29.9 \%$ & $2.0 \%$ & $22.7 \%$ & $43.2 \%$ & $21.3 \%$ & $10.8 \%$ \\
\hline
\end{tabular}

We then examined median estimated gains in value over the 2017 period by ethnoracial groups in the 15 metropolitan areas, combined. Table 2 indicates that in these 15 metros as a group, Black homeowners tended to see substantial appreciation of the homes they purchased in 2012. The median Black homebuyer in the 15 metros experienced an estimated 38.2 percent appreciation in home value over the 5 -year period, compared to 29.9 percent for Whites. Latino buyers experienced particularly high levels of appreciation because, as will be examined more closely below, they were disproportionately located in metropolitan areas such as Riverside and Los Angeles that experienced very high-appreciation rates from 2012 to 2017.

Table 2 also provides the distribution of gains, including the share of buyers who experienced nominal appreciation of less than 5 percent, which is roughly the amount of a real estate agent's commission. Adding modest inflation over this period (less than 7 percent over five years), such homebuyers would end up in a financially negative position if they sold in 2017. However, given the overall gains in most markets, few 2012 buyers of any ethnoracial group purchased in neighborhoods that did not appreciate by more than 5 percent over this period.

Looking particularly at Black buyers in the 15 metros, almost 75 percent of homes purchase by Blacks appreciated over 20 percent from 2012 to 2017, and almost 48 percent appreciated over 40 percent during this period. Only 3.2 percent gained 5 percent in value or less, or lost value, over this period. About 32 percent of 2012 homes purchased by Whites experienced estimated gains of over 40 percent over the 5-year period, substantially lower than the 48 percent of Black home purchases. It was also far below the 86 percent of homes purchased by Latinos experiencing over 40 percent appreciation. Again, this is at least partly due to the fact that many Latino buyers were located in very high-appreciation metros such as Riverside and Los Angeles.

Table 3 gives the estimated median appreciation rates for different ethnoracial groups within each of the 15 metros. Because we expect that metro-level appreciation will affect appreciation rates at the neighborhood level, the metros are ordered from lowest to highest metropolitan appreciation, from St. Louis at 13.8 percent to Sacramento at 66.2 percent. We also group the 15 metros into three levels of appreciation levels, low, medium, and high. Table 3 suggests that metros with substantially higher overall appreciation rates drove estimated appreciation rates for all ethnoracial groups in those metros. Buyers in 2012 of any ethnoracial group in Riverside or Los Angeles, for example, tended to experience much greater gains in home values than buyers of any ethnoracial group in St. Louis or Cincinnati. Thus, metropolitan context was extremely important 
TABLE 3. Median Estimated Appreciation (Nominal) 2012 to 2017, 15 Metropolitan Areas

\begin{tabular}{|c|c|c|c|c|c|c|}
\hline \multirow[b]{2}{*}{ Metro Type } & \multirow{2}{*}{$\begin{array}{l}\text { Metropolitan } \\
\text { Area }\end{array}$} & \multirow{2}{*}{$\begin{array}{l}\text { Metro Appreciation } \\
2012 \text { to } 2017\end{array}$} & \multicolumn{4}{|c|}{ Race/Ethnicity of Homebuyer } \\
\hline & & & Black & Latino & White & Asian \\
\hline \multirow[t]{6}{*}{ Low appreciation } & St. Louis & $13.8 \%$ & $11.8 \%$ & $15.6 \%$ & $16.6 \%$ & $20.3 \%$ \\
\hline & Birmingham & $14.4 \%$ & $10.3 \%$ & $11.6 \%$ & $13.5 \%$ & $16.9 \%$ \\
\hline & Cincinnati & $15.5 \%$ & $14.3 \%$ & $16.6 \%$ & $16.5 \%$ & $16.6 \%$ \\
\hline & Indianapolis & $18.3 \%$ & $18.3 \%$ & $19.4 \%$ & $19.4 \%$ & $19.5 \%$ \\
\hline & Louisville & $18.6 \%$ & $18.6 \%$ & $18.3 \%$ & $18.3 \%$ & $17.1 \%$ \\
\hline & Richmond & $19.2 \%$ & $17.4 \%$ & $20.7 \%$ & $18.6 \%$ & $18.6 \%$ \\
\hline \multirow[t]{4}{*}{ Medium appreciation } & Columbus & $26.9 \%$ & $29.1 \%$ & $29.2 \%$ & $27.4 \%$ & $27.5 \%$ \\
\hline & Boston & $26.9 \%$ & $40.2 \%$ & $37.3 \%$ & $26.6 \%$ & $30.4 \%$ \\
\hline & Raleigh & $27.0 \%$ & $24.4 \%$ & $24.9 \%$ & $24.9 \%$ & $24.7 \%$ \\
\hline & Minneapolis & $30.6 \%$ & $37.2 \%$ & $34.1 \%$ & $31.2 \%$ & $33.1 \%$ \\
\hline \multirow[t]{5}{*}{ High appreciation } & Nashville & $41.1 \%$ & $44.3 \%$ & $43.4 \%$ & $38.5 \%$ & $40.1 \%$ \\
\hline & Atlanta & $42.4 \%$ & $49.9 \%$ & $52.8 \%$ & $45.6 \%$ & $50.4 \%$ \\
\hline & Los Angeles & $51.1 \%$ & $69.2 \%$ & $62.0 \%$ & $49.8 \%$ & $48.9 \%$ \\
\hline & Riverside & $65.4 \%$ & $70.2 \%$ & $76.2 \%$ & $65.6 \%$ & $58.9 \%$ \\
\hline & Sacramento & $66.2 \%$ & $79.2 \%$ & $81.3 \%$ & $63.1 \%$ & $71.9 \%$ \\
\hline
\end{tabular}

to the financial return on homebuying, although generally, median appreciation was still significantly positive and enough to compensate for sales commissions and inflation (15 percent or more) even in most of the weaker market metros. Cincinnati, Birmingham, and St. Louis are the three metros where appreciation was weak enough over this period that some groups had median appreciation rates of less than 15 percent.

In the high- and medium-appreciation metros, the estimated median appreciation of homes purchased by Blacks and Latinos tended to exceed those purchased by Whites. The one exception here is Raleigh. This may be partly due to localized housing market or gentrification pressures in places where they purchased homes. It may also be partially due to the fact that the homes purchased by Blacks and Latinos tend to have lower values initially than those purchased by Whites in the same metropolitan areas, so therefore had more "room" to appreciate. While not experiencing as much appreciation as these metros, Boston also stands out for estimated appreciation rates among Black and Latino buyers that were sizably greater than those among Whites. In weaker market metropolitan areas, especially in St. Louis and Birmingham, estimated Black appreciation rates lagged that of Whites.

Figure 2 provides confidence intervals for ethnoracial group means for each metropolitan area. The 15 metros are divided into the low-, medium- and high-appreciation groups and intervals are shown just for Blacks, Whites, and Latinos for graphic clarity. The figure shows that Black buyers had significantly lower mean appreciation rates than White buyers in four of the six low-appreciation metros, and these four were the four lowestappreciating metros, St. Louis, Birmingham, Cincinnati, and Louisville. In Indianapolis and Richmond, the mean appreciation for Blacks was slightly lower but not statistically significant using 95 percent confidence intervals.

In three of the four medium-appreciation metros, mean Black appreciation was higher than mean White appreciation, with Raleigh being the metro with slightly higher appreciation among Whites. Blacks buyers did particularly well in terms of appreciation in Minneapolis and, especially, Boston. 
CITY \& COMMUNITY

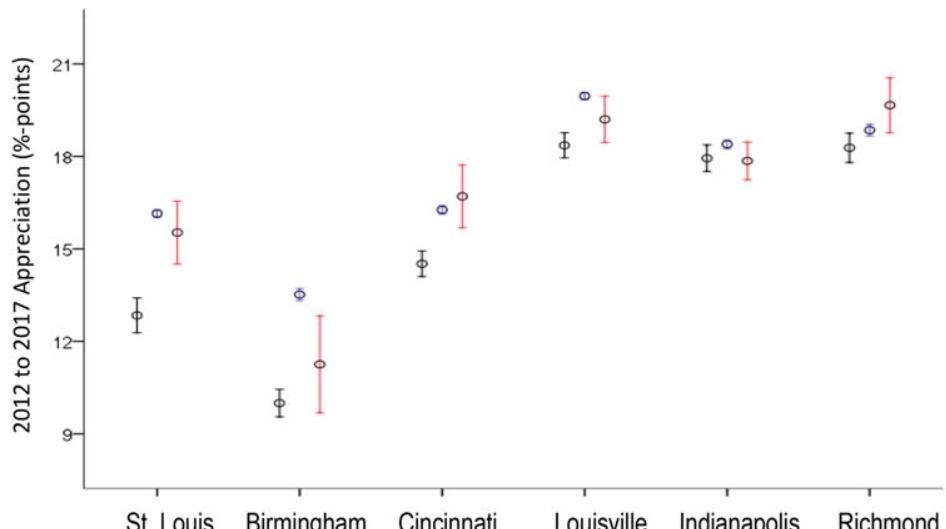

I Black

I White

I Latino
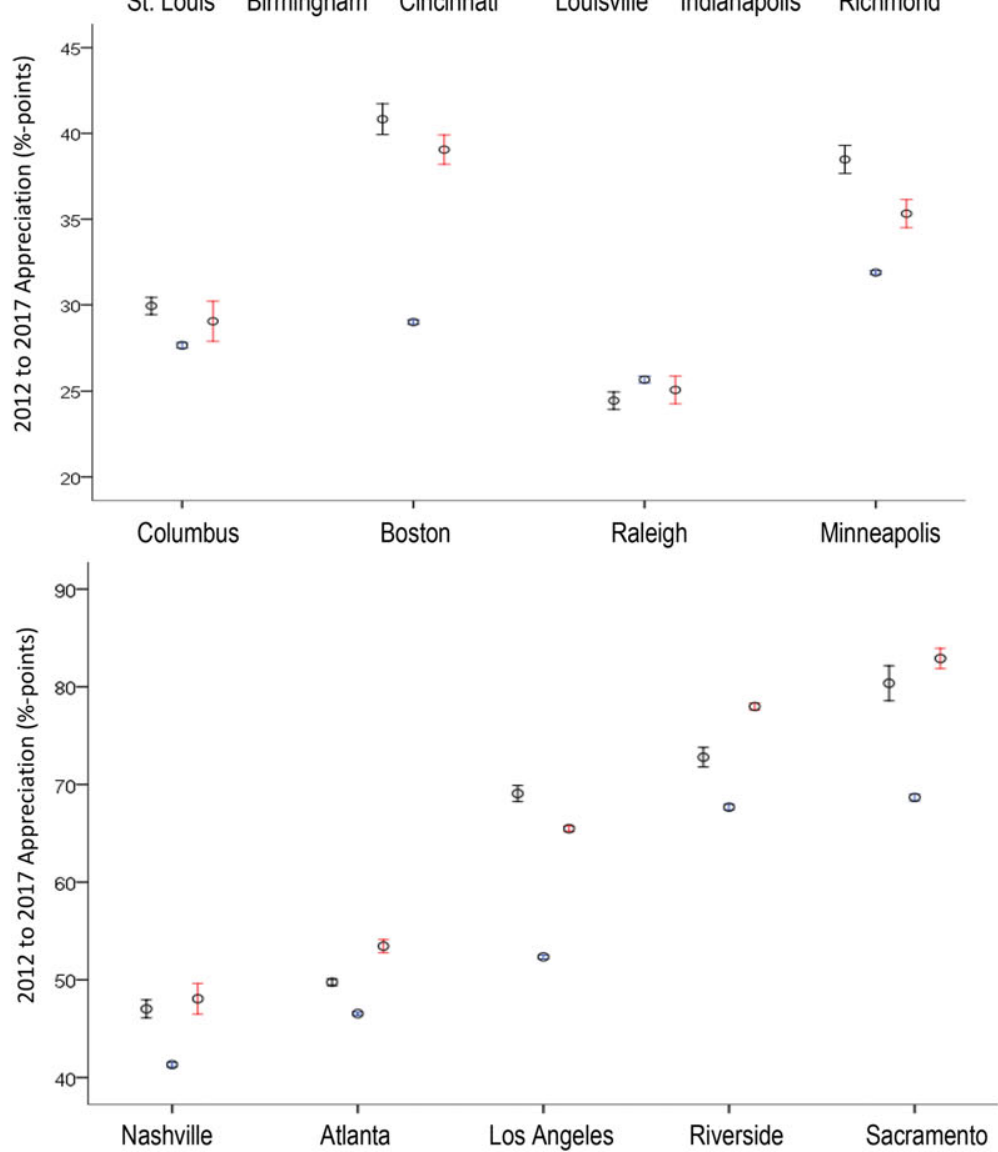

FIG. 2. 95-percent confidence interval plots for mean 2012 to 2017 appreciation rates by race/ethnicity for 15 metros (low-growth, medium growth, and high-growth metros). [Color figure can be viewed at wileyonlinelibrary.com] 

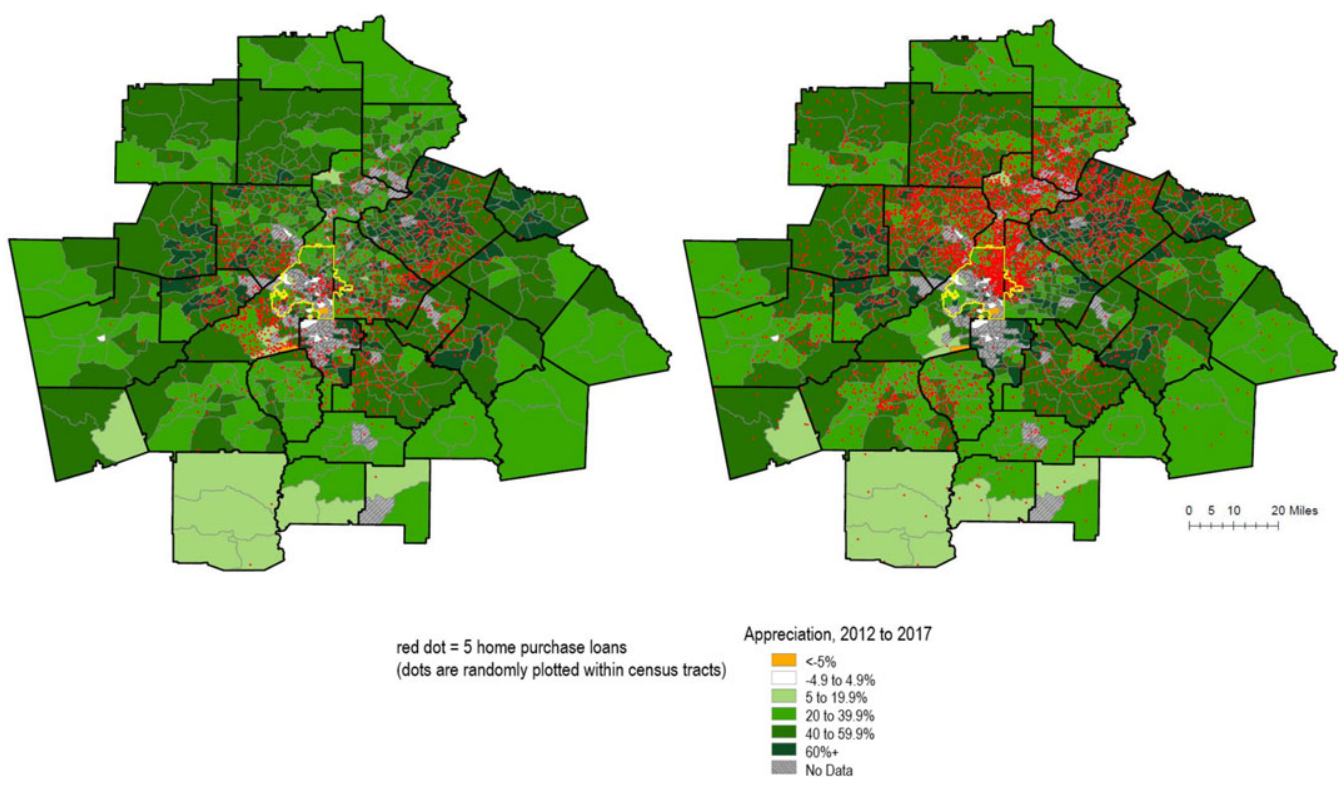

FIG. 3. Black and White homebuying in 2012, against 2012 to 2017 appreciation rates, Atlanta metropolitan area. [Color figure can be viewed at wileyonlinelibrary.com]

In all five of the high-appreciation metros, both Black and Latino 2012 buyers experienced significantly higher appreciation rates than White buyers. In two metros, Atlanta and Riverside, Latino buyers experienced significantly higher appreciation than Blacks, while in one, Los Angeles, Black buyers experienced significantly higher appreciation than Latinos.

\section{LOOKING MORE CLOSELY AT HOMEBUYING AND APPRECIATION IN TWO METROS}

Figures 3 and 4 illustrate the locations of Black and White 2012 homebuyers versus home value appreciation (by census tract) from 2012 to 2017 for two of the 15 metros. They illustrate the varied distributions of Black homebuyers in the two metros and the extent to which they purchased in areas experiencing higher versus lower appreciation.

Black buyers were less spatially concentrated in Atlanta, and constitute a significant presence in various, but not all, parts of the region, whereas in St. Louis, Black homebuying was more spatially concentrated and much of this concentration was in census tracts experiencing modest (less than 20 percent) appreciation over the 5-year period. Because Atlanta is a high-appreciation metro, there are many more census tracts with high-appreciation rates, and Blacks purchased significantly in such tracts, while many Whites purchased homes in the northern-central suburbs which tended to see modest appreciation rates over this period. In St. Louis, Whites were more likely than Blacks to purchase in tracts with somewhat higher appreciation rates. 

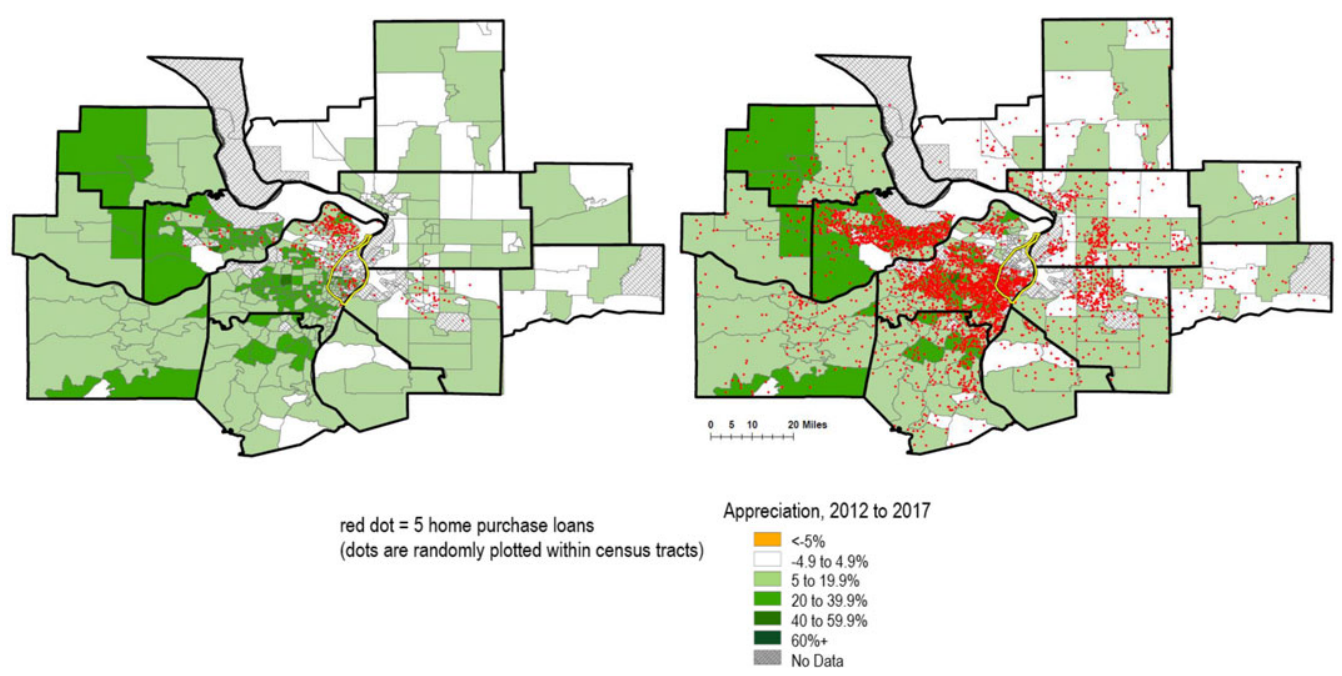

FIG. 4. Black and White homebuying in 2012, against 2012 to 2017 appreciation rates, St. Louis metropolitan area. [Color figure can be viewed at wileyonlinelibrary.com]

TABLE 4. Estimated 5-year Gains in Real Housing Wealth for 2012 Black Homebuyers in 15 Metros, Actual and Under Increased Black Homebuying Scenarios ${ }^{1}$

\begin{tabular}{lccc}
\hline \hline & $\begin{array}{c}\text { Black } \\
\text { Share }\end{array}$ & $\begin{array}{c}\text { Black } \\
\text { Homebuyers }\end{array}$ & $\begin{array}{c}\text { Total Real Gain } \\
\text { (Billions, 2017\$) }\end{array}$ \\
\hline Actual number of Black homebuyers in 2012 & $6.80 \%$ & 26,093 & $\$ 1.71 \mathrm{~B}$ \\
If increased to \% of homeowners & $9.30 \%$ & 35,897 & $\$ 2.36 \mathrm{~B}$ \\
If increased by ratio of \# 2001 Black loans in US & $\mathrm{N} / \mathrm{A}$ & 58,187 & $\$ 3.82 \mathrm{~B}$ \\
\cline { 2 - 4 } \# 2012 Black loans in US & & & \\
\hline
\end{tabular}

${ }^{1}$ Assumes homebuyers own their homes for at least 5 years.

\section{EXAMINING WEALTH GAINS FROM 2012 BLACK HOMEBUYING}

Table 4 looks at the aggregate gain in home value for Black buyers across the 15 metros for the 2012 to 2017 period. The first line shows that approximately 26,000 Black buyers saw real (inflation-adjusted) estimated appreciation of their home values of $\$ 1.71$ billion in total. This works out to an average real gain of over $\$ 65,000$ per homebuyer in 2017. Of course, buyers of more expensive homes and buyers in higher-appreciation metros tended to see substantially larger gains than this, and buyers of less expensive homes and those in lower-appreciation metros mostly saw lower gains than this. Nonetheless, the overall gains in Black wealth are far from trivial and allowed these homebuyers to share in at least some of the widespread wealth gains that other homeowners saw during this period.

Table 4 also provides estimates of 5-year increases in Black housing wealth in the 15 metros under two alternative, hypothetical scenarios. These figures are provided to illustrate the greater wealth that Black homebuyers, as a group, would have attained if 2012 Black homebuying had occurred at higher levels. The first increases 2012 Black 
buying to be equivalent to the share of homeowners in these 15 metros who are Black. The second alternative multiplies the actual 2012 level by the ratio of national Black home purchase loans in 2001 to the level in 2012. This uses figures from Goodman et al. (2014), who estimate the number of "missing" home purchase loans in 2012. These scenarios result in real wealth gains ranging from $\$ 2.4$ to $\$ 3.8$ billion if Black homebuying had been at significantly higher levels. The second scenario would have more than doubled the number of homeowners, as well as the resulting wealth gains over this five-year period. It is important to note that these gains are from just one year of Black homebuying in just these 15 metros.

While $\$ 1.7$ to 3.8 billion in gains due to one year of homebuying are not at all trivial, and the average gain to a 2012 buyer was $\$ 65,000$ over 5 years, it is important to keep in mind the massive amount of wealth that was lost by Black homeowners during the crisis prior to 2012. In comparing 2007 to 2012 3-year ACS estimates in these 15 metros, almost one million Black homeowners saw their home values decline by about $\$ 41$ billion, with an average decline of about $\$ 42,000$ each. ${ }^{5}$ Moreover, many were pushed out of homeownership altogether.

\section{MULTIVARIATE ANALYSIS OF HOMEBUYING FACTORS ASSOCIATED WITH GREATER HOME APPRECIATION}

We now examine the factors associated with higher versus lower levels of appreciation over the 2012 to 2017 period for homebuyers in the 15 metros. We first estimate a model for all 15 metros as a group, with fixed-effect dummy variables for each of the metros (14 dummies). We then repeat the model for three subgroups of metros: low-appreciation, medium-appreciation, and high-appreciation metros. The focus will be on the association between the race or ethnicity of the homebuyer and the ethnoracial composition of the census tract within which the home is located. The basic model is as follows:

$$
\mathrm{A}_{2012-2017}=\alpha+\beta_{1} \mathrm{I}_{2012}+\beta_{2} \mathrm{~V}_{2012}+\boldsymbol{\beta}_{\mathbf{3}} \mathbf{R}+\boldsymbol{\beta}_{\mathbf{4}} \mathbf{S}+\boldsymbol{\beta}_{\mathbf{5}} \mathbf{N}+\boldsymbol{\beta}_{6} \mathbf{M}
$$

where $A_{2012-2017}$ is the estimated appreciation rate for the home from 2012 to 2017; $I_{2012}$ is the income of the buyer in 2012 and comes from the HMDA data, $\mathrm{V}_{2012}$ is the estimated value of the home in 2012 derived principally from the HMDA data as described above, $\mathbf{R}$ is a set of dummies indicating whether the buyer is Black, Latino, Asian, Other, or Unknown (White being the omitted category) also from the HMDA data; $\mathbf{S}$ is a set of tractlevel characteristics, including the poverty rate, the owner-occupancy rate, median family income, and the share of workers commuting over 30 minutes; $\mathbf{N}$ is a set of dummies indicating the ethnoracial mix of the census tract, with dummies for 75 percent or more White, 50-74 percent White, 50 percent or more Black, 50 percent or more Latino, and 50 percent or more Asian (the omitted category is ethnoracially diverse); and finally, $\mathbf{M}$ is a set of dummies for the metropolitan areas included in the regression. The tract-level characteristics come from the 2016 5-year estimates of the American Community Survey, and so are centered on the year 2014.

The results of the four regressions (one for all metros and then one for each of the appreciation types) are shown in Table 5. Comparing the full 15-metro results to the results for each of the three appreciation groups indicates that there are substantial differences 


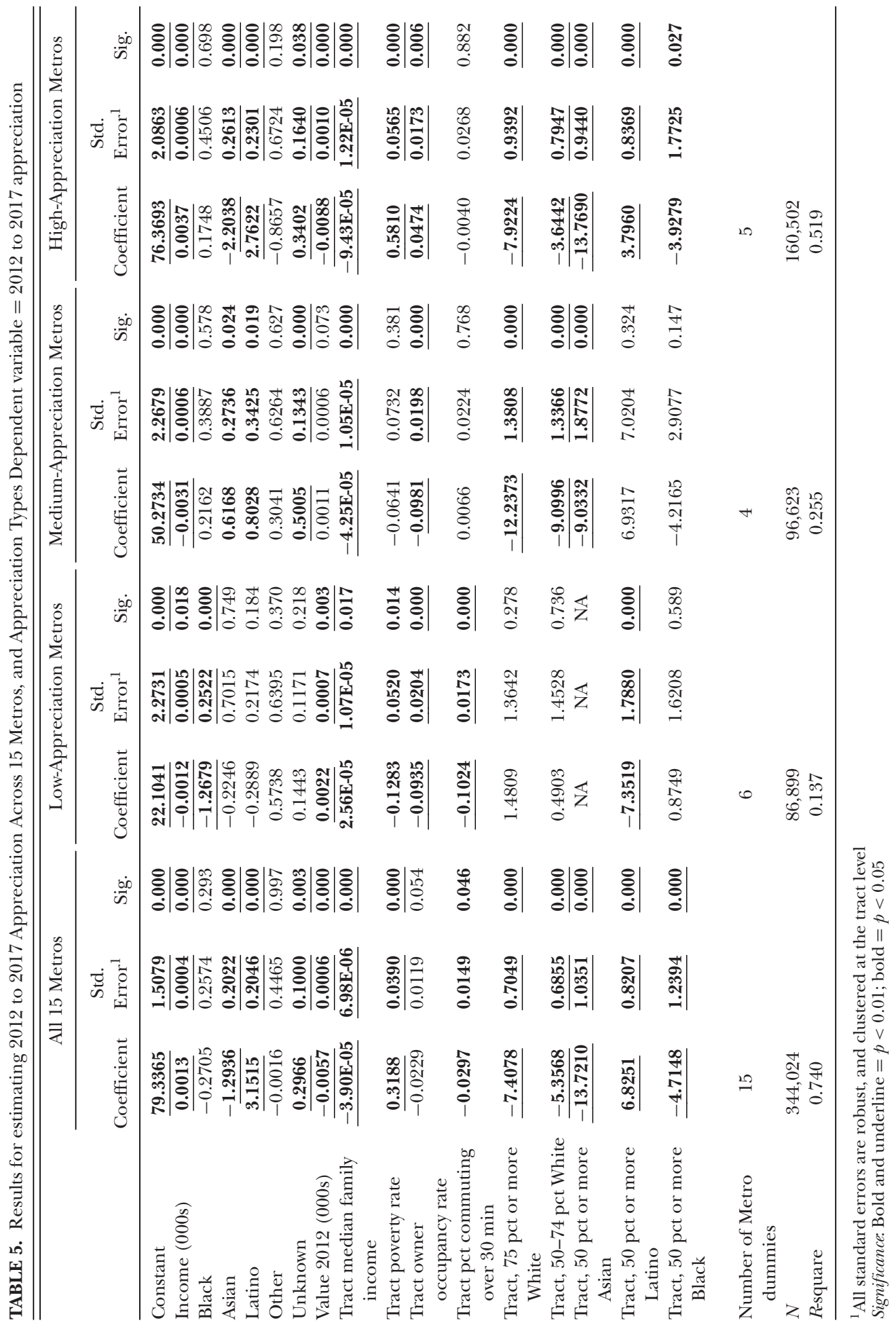


in the associations between the independent variables and the dependent variable across the three different types of metros. Looking first at the race/ethnicity of the buyer, controlling for other factors-including the racial composition of the tract in which they buy homes-Black buyers tended to experience lesser appreciation than White buyers in lowappreciation metros but not in medium- or high-appreciation metros, where there was not a statistically significant difference. Latino buyers in medium- and especially highappreciation metros experienced greater appreciation than White buyers.

A notable difference among the three types of metros is the relationship between neighborhood economic conditions and appreciation. In medium- and highappreciation metros, homes purchased in lower-income and higher poverty neighborhoods tended to experience greater appreciation than those purchased in higher-income tracts. However, in low-appreciation metros, the results are in the opposite direction, with lower-income and higher poverty tracts, other things equal, tending to experience lower levels of appreciation. These results may be consistent with greater likelihoods of gentrification and central-city housing market pressures in higher-appreciation metros, while lower-appreciation metros may be continuing to suffer from weaker appreciation pressures in lower-income neighborhoods, many of which are located in central cities or distressed suburbs.

The last five variables are dummies that indicate the ethnoracial composition of the home. The omitted categories are diverse neighborhoods where no ethnoracial group constitutes a majority of the population. The coefficients on these dummies indicate the effect of being in a tract falling into the ethnoracial category compared to being in a diverse tract. The 15-metro results suggest lower levels of expected appreciation, other things equal, when buying in Asian, White, and Black tracts, compared to buying in a diverse tract, but suggest a positive association with buying in a majority Latino tract. However, the negative coefficient on 75 percent White tracts is substantially larger in magnitude than the coefficient on majority Black tracts, suggesting that buyers in Black tracts did better, on average, than buyers in predominantly White tracts, controlling for other buyer and home characteristics. The difference is substantial, at approximately 9 percentage points.

Again, however, the results vary substantially across the different metropolitan groups. The appreciation premium for buying in Black vs. predominantly White tracts disappears in low-appreciation metros, and the Latino premium found in the 15-metro results actually becomes negative in the low-appreciation metros, but positive in the other two metro types, although the results are not statistically significant in medium-appreciation metros. Latino neighborhoods may be more subject to gentrification pressures in highappreciation metros than in medium- and, especially, low-appreciation metros.

The results in Table 5 suggest that other things held constant, buyers in diverse tracts experienced substantially higher-appreciation rates than those in White or Asian tracts in medium- and high-appreciation metros. In high-appreciation metros, buyers in Latino neighborhoods fared even better, but buyers in Black tracts did somewhat worse than those in diverse tracts (but still better than buyers in predominantly White or Asian neighborhoods). These findings suggest that diverse neighborhoods may have an appreciation premium compared to other neighborhoods, at least in medium- and high-appreciation metros. This suggests that pro-integrative fair housing efforts may support not only ethno diversity but also home value appreciation. 


\section{CONCLUSIONS AND IMPLICATIONS FOR HOUSING POLICY AND PRACTICE}

In the 15 metros studied here, the median 5-year estimated appreciation for Blacks buying homes in 2012 was 38.2 percent, substantially higher than the 29.9 percent median for White buyers. Latino homebuyers saw particularly strong appreciation (63.7 percent median) because they were disproportionately located in high-appreciation metros, such as Los Angeles and Riverside.

The strength of the metropolitan housing market is an extremely important driver of appreciation across all ethnoracial groups. In metros experiencing strong appreciation, all ethnoracial groups saw 5-year median appreciation rates of over 40 percent.

Whether Black buyers experienced stronger appreciation than Whites depended a great deal on the strength of the metropolitan housing market. Black buyers had significantly lower mean appreciation rates than White buyers in four of the six low-appreciation metros, and these four were the four lowest-appreciating metros, St. Louis, Birmingham, Cincinnati, and Louisville. In the remaining two low-appreciation metros, Indianapolis and Richmond, the mean appreciation for Blacks was slightly lower but not statistically significant using 95 percent confidence intervals.

Conversely, in three of the four medium-appreciation metros, mean Black appreciation was higher than mean White appreciation, with Raleigh being the metro with slightly higher appreciation among Whites. Black buyers did particularly well in terms of appreciation in Minneapolis and, especially, in Boston. However, these two metros have relatively modest Black populations. In all five of the high-appreciation metros, both Black and Latino 2012 buyers experienced significantly higher appreciation rates than White buyers. In two metros, Atlanta and Riverside, Latino buyers experienced significantly higher appreciation than Blacks, while in one, Los Angeles, Black buyers experienced significantly higher appreciation than Latinos.

Estimated 5-year gains for the roughly 26,000 Black homebuyers in 2012 in these 15 metros amounts to over $\$ 1.7$ billion in 2017 , assuming buyers own their homes for at least five years. This corresponds to an average of about $\$ 65,000$ in real wealth gain per buyer. Under various scenarios of greater Black buying in 2012, this number increases to a level ranging from $\$ 1.9$ billion to $\$ 3.8$ billion.

The multivariate analysis suggests that the relationships between individual- and neighborhood-level covariates and home value appreciation depends on the metropolitan context. In medium- and especially high-appreciation metros, homes purchased in lower income neighborhoods and more racially diverse neighborhoods, controlling for other factors, experienced greater levels of appreciation than those purchased in predominantly White and higher-income neighborhoods. These findings should support fair housing efforts in these sorts of metros. However, in low-appreciation metros, there was no statistical difference in appreciation rates associated with racial composition, with one exception. Latino neighborhoods were associated with lower appreciation rates, other things equal.

The first implication of the findings in this paper is that "metro matters." Black homebuyers, as well as homebuyers more generally, are much more likely to fare well financially in appreciating metros. Moreover, Black homebuyers have done particularly well-compared to White buyers-in metros with strong housing markets, but have 
lagged Whites in weaker metros. Housing counselors, policy makers and others should pay particular attention to metro-level housing market trends. In shrinking or declining metros, promoting homeownership should be done carefully and consider possible stagnant home value trends. Of course, there are reasons for promoting homeownership other than asset-building, but the financial aspects should be part of the decision-making and policymaking process.

Policymakers and practitioners should also pay attention to regional data that may indicate an overvaluation of housing in the metropolitan market. Purchasing a home in 2012 at the bottom of the appreciation cycle provided buyers with substantial assetbuilding opportunities. But as the top of a market cycle draws near, purchasing becomes somewhat riskier. While a better-regulated mortgage market suggests that most metros are not due for a sudden collapse in values of the sort experienced in the late 2000s, the possibility of declines in value certainly remain. Local housing financing programs should factor the housing market cycle into their underwriting, especially focusing on moderating payment-to-income ratios when the market may be reaching the top of a cycle to reduce the risk of default.

In suggesting that promoting increased Black homebuying will provide for substantial gains in Black housing wealth, we need to keep in mind the lessons of the subprime crisis. After the crisis, and the Dodd-Frank Act mortgage market reforms, Blacks were generally able to buy in neighborhoods where their homes gained in value without the risks, high costs, and predatory features that had been common in the 2000s. High interest rates or fees can erode the gains made via appreciation. Moreover, foreclosure will do even more harm. Thus, it is critical to view Black homebuying as a path towards wealth-building in the context of the consumer protections and was made possible through increased mortgage regulation and the availability of affordable Federal Home Administration (FHA) loans.

Maintaining strong consumer protections adopted under the 2010 Dodd-Frank Act may be the single-most important requirement for constraining downside risks to Black homeownership. High-risk, high-cost, and frequently predatory mortgage lending results in a high propensity for failed homeownership. Even if a homeowner maintains ownership of her home, high financing costs or barriers to refinancing when mortgage rates decline will reduce the financial return on ownership, potentially making it a losing proposition. Maintaining the Qualified Mortgage and Ability to Repay regulations, and a strong and assertive Consumer Financial Protection Bureau (CFPB), are especially important here. In the event that CFPB enforcement wanes, state mortgage regulators should increase enforcement activities.

Providing for robust and affordable FHA lending programs, which Black buyers disproportionately rely on and which provide for smaller downpayments, is important. The FHA proved to be a critical countercyclical source of home lending during the mortgage crisis when other parts of the mortgage market pulled back severely, especially from Black neighborhoods and borrowers (Immergluck 2011). There is the potential for the FHA to be an even stronger countercyclical force in the event of regional or national housing downturns.

It is critically important to limit the extent of risk-based loan pricing, a practice in which borrowers with lower credit scores and/or lower downpayments pay substantially higher interest rates. This has the perverse effect of increasing the housing cost burden for such households and thereby raising the risk of foreclosure and making it more diffi- 
cult for them to maintain some savings in the event of an adverse event such as job loss. Proposals to privatize or partially privatize the secondary mortgage market would likely result in greater levels of risk-based pricing and could prove highly detrimental to Black homeownership and home values in Black neighborhoods (Immergluck 2015).

Local and state policymakers should provide carefully designed downpayment assistance programs aimed at moderate-income homebuyers. Policymakers should also consider providing or increasing the availability of low-downpayment, affordable mortgages through mortgage revenue bond programs. Another vehicle for policymakers and funders to provide affordable home financing is via supporting community development financial institutions (CDFIs), either those based locally, or by encouraging a national CDFI to establish operations in the area.

Finally, stronger fair housing and community reinvestment policy and enforcement are critical to better support Black homebuying and appreciation in Black and diverse neighborhoods. The findings above show that homes in diverse neighborhoods generally appreciated as well or better than homes in other neighborhoods, and this finding can be used to support fair housing and fair lending efforts. Fair housing enforcement efforts to prevent the steering of homebuyers into same-race neighborhoods should be supported at all levels of government. Recent retrenchment at the federal level in the fair housing space, including not implementing the Affirmatively Furthering Fair Housing rules, is not helpful in this regard.

Fair lending enforcement is the responsibility of federal bank regulators, the U.S. Department of Housing and Urban Development (HUD), and the CFPB. A focus on large lenders and lenders active in metros with substantial Black populations will support Black homeownership. Attention to disparate impact, as well as disparate treatment, discrimination is also important. In the community reinvestment arena, maintaining attention to localized or regional assessment areas in the enforcement of the Community Reinvestment Act (CRA) is critical. In the long run, the expansion of CRA to cover all mortgage lenders, including mortgage companies, could have a significant impact on improved access to credit in Black neighborhoods and for prospective Black homebuyers.

\section{Notes}

${ }^{1}$ The ability of lenders to go after borrowers' assets beyond taking the home through foreclosure (referred to as pursuing "recourse") varies according to state foreclosure law. However, even in recourse states "restrictions on deficiency judgements render many loans effectively nonrecourse" (Campbell and Cocco 2014).

${ }^{2}$ We only include first-lien home purchase loans in all analyses of HMDA data in this study.

${ }^{3}$ We do not consider the presence of second-lien home purchase loans in estimating the initial purchase price. Only 2 percent of first-lien home-purchase loans in HMDA in 2012 and 2017 had associated second-lien loans.

${ }^{4}$ We assume that all homes in the same census tract appreciate at the same rate over the 5-year period. Much of the following analysis also assumes that 2012 homebuyers own their homes during this period. While it is possible that there are systematic differences in within-tract appreciation that may affect Black buyer appreciation differently than that of other buyers, there is no way to test this with the available data. Moreover, researchers at the Federal Housing Finance Agency who derived the tract HPI also attempted to develop census block-ground HPIs (a smaller unit of geography) but found that their predictive power was generally no better (and somewhat noisier) than the tract-level index (Bogin et al. 2016b). 


\begin{abstract}
${ }^{5}$ These estimates were obtained by calculating the average Black home value in the 3-year 2007 IPUMS ACS sample and the 3-year 2012 IPUMS ACS sample for each of the 15 metros. These averages were applied to the total number of Black homeowners in each of the 15 metros in 2007 and 2012, using the 3-year ACS to generate total Black-owned home value. No effort was made to estimate net equity in the homes, as these data are not readily available in the ACS. Also, no effort was made to estimate any recovery in home values among existing Black homeowners after 2012.
\end{abstract}

\title{
REFERENCES
}

Bayer, Patrick, Fernando Ferreira, and Steven Ross. 2017. "What Drives Racial and Ethnic Differences in HighCost Mortgages? The Role of High-Risk Lenders." The Review of Financial Studies 31:175-205.

Bhutta, Neil, and Daniel Ringo. 2014. “The 2013 Home Mortgage Disclosure Act Data.” Federal Reserve Bulletin $100(6): 1-37$.

Boehm, Thomas, and Alan Schlottmann. 2004. "Wealth Accumulation and Homeownership." U.S. Department of Housing and Urban Development. December. https://www.huduser.gov/publications/pdf/ wealthaccumulationandhomeownership.pdf.

Bostic, Raphael, and Kwan Lee. 2009. "Homeownership: America's Dream.” Pp. 218-56 in Insufficient Funds: Savings, Assets, Credit, and Banking Among Low-income Households, edited by Rebecca M. Blank and Michael S. Barr. New York, NY: Russell Sage Foundation, .

Bogin, Alexander, William Doerner, and William Larson. 2016a. "Local House Price Dynamics: New indices and Stylized Facts." Working Paper 16-01. Federal Housing. Finance Agency. June.

—. 2016b. "Missing the Mark: House Price Index Accuracy and Mortgage Credit Modeling." Working Paper 16-04. Federal Housing Finance Agency. September.

Bucholz, David, Jeff Larrimore, and Jeff Thompson. 2016. "Federal Reserve Surveys of the Economic Well-Being of US Households: SCF and SHED." Urban Institute. Retrieved January 21, 2016 (https://www.urban.org/sites/default/files/urban institute data talk'scf shed combinedv2.pdf).

Campbell, John, and Jose Cocco. 2014. "A Model of Mortgage Default." Retrieved February, 2014 (https://scholar.harvard.edu/files/campbell/files/mortdefault13022014.pdf).

Dickerson, Mechele. 2012. "Public Interest, Public Choice, and the Cult of Homeownership." UC Irvine Law Review 2:843-69.

Drew, Rachel. 2018. "Housing Vacancy Survey Report. Enterprise Community Partners.” Retrieved July 26 (https://www.enterprisecommunity.org/policy-and-advocacy/housing-vacancy-survey-report).

Emmons, William. 2017. "Homeownership and the Racial Wealth Divide." Housing Perspectives. Federal Reserve Bank of St. Louis. Retrieved July 2017 (https://www.stlouisfed.org/ /media/Publications/ Housing-Market-Perspectives/2017/Issue-5/HMP'issue5 web2.pdf).

Faber, Jacob, and Ingrid Gould Ellen. 2016. "Race and the Housing Cycle: Differences in Home Equity Trends among Long-Term Homeowners." Housing Policy Debate 26:456-73.

Federal Reserve Board. 2017. "SCF Chartbook." Federal Reserve Board. Retrieved October 17 (https://www.federalreserve.gov/econres/files/BulletinCharts.pdf).

Goodman, Laurie, Jun Zhu, and Taz George. 2014. "Where Have All the Loans Gone? The Impact of Credit Availability on Mortgage Volume." Journal of Structured Finance 20 (2): 45-53.

Goodman, Laurie, and Christopher Mayer. 2018. "Homeownership and the American Dream." Journal of Economic Perspectives 32:31-58.

Grinstein-Weiss, Michal, Clinton Key, Shenyang Guo, Yeong Hun Yeo, and Krista Holub. 2013. "Homeownership and Wealth among Low- and Moderate-Income Households. Housing Policy Debate 23:259-79.

Herbert, Christopher, Daniel McCue, and Rocio Sanchez-Moyano. 2013. "Is Homeownership Still an Effective Means of Building Wealth for Low-Income and Minority Households? (Was It Ever?)." Harvard Joint Center for Housing Studies. HBTL-06. Retrieved September 2013 (http://www.jchs.harvard.edu/sites/default/files/hbtl-06.pdf).

Immergluck, Dan. 2009. Foreclosed: High-risk Lending, Deregulation, and the Undermining of America's Mortgage Market. Ithaca: Cornell University Press.

- 2011. "From Minor to Major Player: The Geography of FHA Lending During the US Mortgage Crisis." Journal of Urban Affairs 33:1-20.

- 2015. Preventing the Next Mortgage Crisis: The Meltdown, the Federal Response, and the Future of Housing in America. Lanham, MD: Rowman and Littlefield. 


\section{CITY \& COMMUNITY}

Newman, Sandra, and C. Scott Holupka. 2016. "Is Timing Everything? Race, Homeownership and Net Worth in the Tumultuous 2000s." Real Estate Economics 44:307-54.

Raymond, Elora. 2018. "Race, Uneven Recovery and Persistent Negative Equity in the Southeastern United States." Journal of Urban Affairs 40:824-37.

Raymond, Elora, Kyungsoon Wang, and Dan Immergluck. 2016. "Race and Uneven Recovery: Neighborhood Home Value Trajectories in Atlanta Before and After the Housing Crisis." Housing Studies 31:324-39.

Reid, Carolina. 2005. "Achieving the American Dream? A Longitudinal Analysis of the Homeownership Experiences of Low-Income Families." Center for Social Development Working Paper 05-20. Available at: https://csd.wustl.edu/Publications/Documents/WP05-20.pdf.

Reid, Carolina, Deborah Bocian, Wei Li, and Roberto Quercia. 2017. "Revisiting the Subprime Crisis: The Dual Mortgage Market and Mortgage Defaults by Race and Ethnicity." Journal of Urban Affairs 39:469-87.

Shapiro, Thomas, Tatjana Meschede, and Sam Osoro. 2013. "The Roots of the Widening Racial Wealth Gap: Explaining the Black-White Economic Divide." Waltham, MA: Institute on Assets and Social Policy, Brandeis University. Available at: https://iasp.brandeis.edu/pdfs/Author/shapiro-thomas$\mathrm{m} /$ racialwealthgapbrief.pdf.

Shlay, Anne. 2015. "Life and Liberty in the Pursuit of Housing: Rethinking Renting and Owning in Post-Crisis America." Housing Studies 30:560-79.

Steil, Justin, Len Albright, Jacob Rugh, and Douglas Massey. 2018. "The Social Structure of Mortgage Discrimination." Housing Studies 33:759-76.

Urban Institute. 2016. "Housing Finance at a Glance: Monthly Chartbook." Retrieved June 2016 (https://www.urban.org/sites/default/files/publication/81726/2000832-Housing-Finance-at-a-GlanceA-Monthly-Chartbook-June-2016.pdf).

2017. "Mortgage Insurance Data at a Glance." Retrieved August 2017 (https://www.urban.org/ sites/default/files/publication/92681/mortgage insurance data at 'a glance chartbook'4.pdf). 